\title{
La leyenda de Izz Al Din Al Qassam y su influencia en la insurgencia palestina
}

\author{
The legend of Izz Al Din Al Qassam and its influence on the Palestinian insurgency \\ Gonzalo CARETTI
}

Universidad Complutense de Madrid

gcaretti@ucm.es

https://orcid.org/0000-0002-9067-5276

Recibido 22/07/2020. Aceptado 24/02/2021

Para citar este artículo: Gonzalo CARETTI (2021): "La leyenda de Izz Al Din Al Qassam y su influencia en la insurgencia palestina" en Revista de Estudios Internacionales Mediterráneos, 30, pp. 42-61.

Para acceder a este artículo: https://doi.org/10.15366/reim2021.30.003

\section{Resumen:}

Dentro de la cultura de insurgencia armada en Palestina, la figura del clérigo Izz Al Din Al Qassam (Siria, 1883 - Palestina, 1935) es una de las más mitificadas. Líder de una revuelta armada en 1935 contra las autoridades del Mandato británico que duró a apenas veinte días, su imagen ha tenido un importante impacto en los movimientos políticos y armados posteriores y en la tradición oral de la zona. Al Qassam ha sido, desde su muerte, un habitual elemento movilizador en la cultura de resistencia contra la ocupación. Éste artículo realiza, a través de un análisis crítico de fuentes bibliográficas y archivísticas, una revisión crítica de su figura y de cómo la leyenda ha influido en las visiones actuales sobre él.

Palabras clave: Descolonización/ Oriente Próximo/ islamismos/ Palestina/Israel/

\section{Abstract:}

Cleric Izz Al Din Al Qassam (Syria, 1883 - Palestine, 1935) is one of the most mythicized figures of the Palestinian anti-colonialist movement. Leader of an armed uprising against the British Mandate's authorities in 1935, which lasted only twenty days, his image has had an important impact on the subsequent political and armed movements, as well as on the region's oral tradition. Since his death, Al Qassam has become a mobilizing resource in the culture of resistance against the occupation. By relying on bibliographical and archival sources, this article undertakes a critical review of his figure and the way his legend has influenced current visions of him.

Keywords: Decolonization/ Middle East/ Islamisms/ Palestine/ Israel/ 


\section{Introducción}

Dice el historiador árabe Mohsen Mohammad Saleh que los palestinos "nunca han estado tan de acuerdo sobre una personalidad como en el caso de Izz al Din Al Qassam" (Mohsen, 2011). La afirmación resulta matizable, ya que el clérigo de origen sirio a menudo continúa siendo una gran incógnita, pero sí es ejemplificadora de su importancia cultural y social. Originario de la provincia de Latakia (Siria), la revuelta armada que encabezó en Palestina en 1935 construyó una influyente leyenda que ha perdurado y servido de referencia en la cultura política palestina desde entonces. Si Hajj Amin Al Husseini, el Gran Muftí de Jerusalén, representa en el imaginario colectivo palestino la influencia y declive del poder religioso institucional, la del clérigo de origen sirio representa al héroe popular de la lucha armada. Pocas figuras modernas han sido tan citadas e idealizadas desde posiciones sociales, políticas y culturales tan diferentes. Se le ha considerado y considera, tanto un padre del nacionalismo palestino como un pionero del activismo islamista ${ }^{1}$ en la zona.

El hecho de que Al Qassam muriese en batalla ha permitido que continúe siendo hoy objeto de veneración en muchos sectores. Su historia inaugura un olimpo de 'héroes' de la 'martirología' de la insurgencia armada, en la que se incluyen personalidades como Abd El Qader Al Husseini o Yassir Arafat. A lo largo de las décadas de lucha y guerrilla del conflicto en Oriente Próximo no han faltado los esfuerzos por utilizar su figura como un aliciente motivador de la resistencia armada contra la ocupación, ya fuera la británica durante el Mandato como la israelí desde 1948.

Sin embargo, ese uso que se ha hecho de él ha generado no pocas distorsiones y confusiones sobre su personalidad. En la historiografía sobre el conflicto palestino israelí a menudo ha sido una mera anécdota que tan sólo ha cobrado cierta relevancia por las menciones que los grupos islamistas armados palestinos de los años 80 han hecho de él. En su intento por adueñarse de ese mito, estos grupos le han devuelto a la actualidad, pero con una contrapartida: la visión del islamismo palestino sobre el clérigo parece haberse adueñado del relato.

La escasa atención que ha recibido también pone otra cuestión sobre la mesa. En realidad, el propio desarrollo de los islamismos ha sido un asunto a menudo ignorado en la mayoría de las monografías que han abordado la descolonización en Oriente Próximo. La influencia de estos movimientos sociopolíticos no es una cuestión reciente que se pueda reducir a los últimos 20 años. Pese a estar presente en Palestina desde los años 20, y tomando a Al Qassam como gran referente, el islamismo sólo ha cobrado relevancia historiográfica con la irrupción del movimiento Hamas, en 1987, y con la primera y la segunda intifada. Pero el desarrollo de este grupo, así como Yihad Islámica Palestina ambos herederos locales del islamismo del Movimiento de los Hermanos Musulmanes (en siglas HHMM), fundado en 1928- se ha producido a lo largo de décadas de configuración de un movimiento que parte de idiosincrasias tan antiguas como los sentimientos nacionalistas y que presenta un modelo distinto para la descolonización.

En ese sentido, Al Qassam es una de sus primeras expresiones. Pero en la cultura de lucha armada en Palestina, es mucho más. Es un mito presente en muchos espectros sociales, y sobre su figura siguen existiendo grandes dudas conceptuales y no pocos malos entendidos: ¿fue un líder nacionalista, un guerrillero anticolonialista o un ideólogo islamista? ¿Fue su guerrilla, como asegura Hamas y algunos historiadores árabes, el detonante de la revuelta palestina de 1936? ¿Perteneció

\footnotetext{
${ }^{1}$ Para "islamismo" recurrimos a la definición de Luz Gómez, "conjunto de proyectos ideológicos de carácter político". (Gómez, 2019: 197).
} 
o no a los HHMM, como fuentes no académicas se empeñan en resaltar? Todavía hoy, sigue estando a medio camino entre la leyenda y la realidad dejando un terreno abonado a los relatos mitificados.

Sin tratar de sobredimensionar su importancia, intentaremos tratar de responder a alguna de esas preguntas en tres pasos. Primero, delimitando hasta dónde llega la leyenda y hasta dónde la historia del hombre. En segundo, identificando el cómo esa leyenda ha impactado en la cultura de lucha armada en Palestina; por último, cómo esa leyenda ha terminado transformando su legado y figura.

Para ello, se parte de una revisión crítica y comparada sobre los principales textos académicos escritos sobre él, un análisis del estado de la cuestión confrontado con una revisión de archivos británicos sobre sus acciones. En esta parte se reevaluará la atención prestada a sus etapas, con el fin de revisar la cierta "palestinización" que, a nuestro juicio, se ha hecho de Al Qassam. En la segunda parte se analiza su impacto en la cultura socio- política palestina, recurriendo, en primer lugar, a un análisis del discurso de las principales organizaciones políticas palestinas que han utilizado a su figura, como Hamas, Yihad Islámica, Hizb At Tahrir, el Frente Democrático para la Liberación de Palestina o El Mando Nacional Unificado. Para ello se analizan documentos, boletines, material gráfico y on line que lo mencionan. Por último, para aproximarse al impacto cultural, se analiza su proyección en la cultura o la prensa.

A menudo, los trabajos sobre el clérigo sirio han centrado su atención casi exclusivamente en su etapa en Palestina. No obstante, tanto o más relevante resultan sus primeros años en Siria. Allí fue donde vivió desde sus años más tempranos el fin de una era, caracterizada por la caída del Imperio otomano y, sobre todo, por la abolición del Califato, decretada por Kemal Atatürk en 1924, y que causó un profundo impacto identitario en el mundo musulmán.

Al Qassam fue, como Hassan Al Banna, fundador de los HHMM, un producto de estas circunstancias. De esa suerte de orfandad que dejó la desaparición del Califato nació un movimiento, el islam político, que empezaba a cobrar forma en diversas vertientes, que se presentaba como una alternativa a la corriente liberal que se inspiraba en los modelos occidentales, y que ha tratado, desde entonces, de rellenar ese vacío sociopolítico. Por eso, circunscribir a Al Qassam a las particularidades locales de la lucha palestina resulta incompleto, por más que se haya convertido con los años en todo un símbolo local.

\section{La etapa en Siria}

Su nombre completo era Izz al Din ibn Abdelkader ibn Mustafa ibn Yusuf ibn Muhammad al Qassam y nació en 1883 en Yabla, región siria de Latakia. Formaba parte de una familia con profundos lazos con las estructuras religiosas sufíes o yama'at, corrientes místicas y tradicionalistas del islam que "centran su acción en el terreno espiritual intentando convertir a los fieles en modelos de piedad" (Álvarez-Ossorio, 2011: 172). Su abuelo tenía una posición importante en las estructuras de una influyente orden local Qadiriyya, y su padre llegó también a colaborar con otra orden de la corriente Naqshbandiya, que abogaba por una mayor ortodoxia en las reglas islámicas, y que tuvo influencia doctrinal entre los intelectuales 'salafiyas'de Damasco' ${ }^{2}$ surgidos en la última década del siglo XIX (Sanagan, 2013: 325; Nafi, 1997: 187). Hasta donde se sabe, la primera educación corrió a cargo del Sheikh (Jeque) Salim Tayarah, un maestro coránico con una gran reputación local y sólidos principios islámicos.

Tras esos primeros años de formación, en los que sin duda los principios islámicos quedaron bien enraizados, Al Qassam viajó en 1902 junto a un grupo de estudiantes a El Cairo para continuar sus estudios en la prestigiosa escuela islámica egipcia Al Azhar, algo muy habitual entre los intelectuales sirios $^{3}$. Fue sin duda allí donde comenzó a formarse su pensamiento político. La época en la que Al

\footnotetext{
${ }^{2}$ Aquí distinguimos entre el movimiento 'salafiya' del siglo XIX y principios del XX y salafismo, movimiento surgido posteriormente, distinción planteada por Gómez y Ramadán (Gómez, 2019: 336; Ramadán, 2000: 53-194).

${ }^{3}$ Un ejemplo representativo es el de Abd al-Rahman Al Kawakibi, un intelectual sirio de finales del siglo XIX, considerado como uno de los precursores del movimiento 'salafiya' en las provincias sirias del Imperio otomano.
} 
Qassam estudió en Al Azhar fue también la del auge de profesores e intelectuales del movimiento de la 'salafiya' como Muhammad Abduh y Rashid Rida, máximos representantes de un movimiento islamista anticolonial que abogaba por el rechazo a toda influencia occidental dentro de la sociedad musulmana y que buscaba el regreso a los principios sociales de las primeras comunidades islámicas. Mark Sanagan, uno de los principales estudiosos del clérigo sirio, señala que no hay pruebas documentales que avalen que Al Qassam llegase a estar tutelado directamente por ninguno de ambos líderes (Sanagan, 2013: 326), pero sí de la influencia que el pensamiento de la 'salafiya' ejerció en su desarrollo intelectual y sus posicionamientos posteriores (Moubayed, 2005: 390-392).

En esta época de juventud se construye también su pensamiento social, así como unos rasgos de personalidad que se repetirán a lo largo de su vida y que acabó transmitiendo a sus seguidores. De ello fue testigo, por ejemplo, su principal compañero y amigo durante esta época, Izz Al Din Al Alam Al Din Al Tanukhi, que años después recordaba sus principales características: un marcado ascetismo y autosuficiencia, una gran sensibilidad por los asuntos sociales y una firme convicción de que era el regreso al islam el que liberaría a las comunidades musulmanas de la dominación extranjera (Scheleifer, 1993: 140; Nafi, 1997: 187).

Aquella estancia en Egipto que se encontraba bajo mandato británico fue determinante porque, además, le permitió obtener el título de alim o maestro. Tras ello regresó a su localidad natal de Jabla en 1904 donde comenzó a predicar en la mezquita Sultan Ibrahim Al Adhan. Allí ejerció también como profesor en una escuela de la localidad asociada a la cofradía sufí qadirí. Esta posición resulta importante a la hora de evaluar su influencia ya que, en una sociedad marcada por las normas tribales y religiosas, el predicador y maestro adquiría una importante autoridad moral.

Ya desde su regreso a Yabla, sus mensajes empezaban a perfilar algunas de las características que marcaron su discurso y, posteriormente, el de sus seguidores. Características, todas ellas, que recordaban a las precisadas por su amigo de estudios Al Tanukhi: un marcado carácter social, una insistencia en la moralidad islámica rigorista, apelaciones constantes a la resistencia frente al colonialismo político y cultural y una fuerte crítica a las instituciones tradicionales del islam. Todos ellos factores influidos por el mensaje del reformismo de la 'salafiya' que tanto le había marcado durante sus años de estudio en El Cairo y que completaban los principios adquiridos en su niñez. Es en esta época, es decir, años antes de su llegada a Palestina, cuando la mentalidad de Al Qassam ya comienza a considerar la yihad o lucha armada como método prioritario. Para referirnos a lo largo de este trabajo a la posible interpretación de Al Qassam sobre el término, utilizaremos tres conceptos: la yihad individual, la yihad social o todos aquellos esfuerzos reformistas no violentos encaminados a reforzar la cultura islámica en la sociedad y, por último, la "yihad por la espada" o armada, la yihad bil saif. ${ }^{4}$

\footnotetext{
${ }^{4}$ El término yihad, como se sabe, es polémico y ha generado no pocos debates. Citado 41 veces en el Corán, literalmente significa "esfuerzo" por instaurar el mensaje del islam en la tierra. Sin embargo, a lo largo de la historia ha tenido distintas interpretaciones y utilizaciones y todavía hoy implica no pocas discusiones entre las autoridades musulmanas. Doctrinalmente, existen dos tipos de yihad: la yihad al kabir o yihad mayor y la yihad al saguir o menor. La primera es la individual y hace referencia a la lucha interna de cada musulmán contra la tentación, el pecado. Sería una obligación personal (fard al ain) a la que están obligados todos los musulmanes; es decir, los esfuerzos individuales por seguir en la vida cotidiana los preceptos del islam. La segunda, la yihad menor, es la lucha encaminada a construir una buena sociedad musulmana, algo que puede incluir, llegado el momento, la acción armada. A menudo ésta se entiende como defensiva frente al ataque contra los fieles, pero esa interpretación de la defensa puede llevar también a la ofensiva; ha habido incluso escuelas de doctrina que han considerado a la yihad como el sexto pilar del islam, si bien es cierto que en el islam sunní oficial nadie la reconoce como tal. Como en tantos otros temas doctrinales del islam, no hay
} 
Estos conceptos de yihad ya estaban presentes en el pensamiento del joven clérigo sirio, incluido el concepto de yihad armada, que ya comenzada a citar en sus primeros sermones en Yabla. Su primera gran referencia se produce como reacción de apoyo al Sultán Mehmed $V$ tras la invasión italiana del norte de África otomano en 1911. También es entonces cuando se producen sus primeras manifestaciones activistas, encargándose de reclutar a jóvenes voluntarios de su localidad que le acompañasen al norte de África en un destacamento de voluntarios para luchar contra la invasión italiana. Según algunos autores, consiguió reclutar a unos 250 hombres (Moubayed, 2005: 390-392) que se autodenominaban luchadores por la yihad (en árabe, muyahidin). Sin embargo, esa primera experiencia concluyó cuando las autoridades otomanas abandonaron la campaña en el norte de África y rechazaron enviar a los voluntarios de Al Qassam a la región, lo que le hizo retornar a Yabla. Su siguiente experiencia militar llegaría tras el estallido de la Primera Guerra Mundial cuando se enroló en el ejército otomano, convirtiéndose en imam de un destacamento militar en Damasco, donde recibió entrenamiento específico en el manejo de armas.

Es conocido que la derrota otomana y la descomposición de su imperio esclerótico generaron un gran cambio social en la sociedad musulmana y, lo más importante, una crisis identitaria. El tratado de Sykes-Picot estableció un reparto del antiguo territorio, pasando las actuales regiones de Siria y Líbano a estar administradas por Francia y de ese reparto surgieron nuevas fronteras y países. Aquello nunca fue aceptado de buen término. Dicho tratado y la colonización derivada de él generaron una reacción árabe encabezada por el rey Faisal I, un antiguo aliado del Reino Unido en la lucha contra los otomanos. Para ellos, esta nueva distribución era una traición y reclamaban el cumplimiento de las promesas hechas por Londres años antes: la formación de un gran reino árabe compuesto por los actuales Irak, Siria, Jordania, Palestina y Líbano.

En este contexto, el de la colonización francesa de Siria, es en el que Al Qassam inicia su primera experiencia guerrillera junto a un grupo de insurgentes de Yabla, que formaban parte de una poco centralizada revuelta en todo el país. Las revueltas, iniciadas a partir de 1919, estaban organizadas en Isabat (es decir, comandos) de entre 30 y 100 hombres tradicionalmente liderados por notables locales o Sheikh. Las tropas francesas inicialmente las subestimaron, considerándolas una suerte de bandas armadas sin organización. Pero esa visión pronto comenzó a cambiar, tal y como recogían los informes locales. En febrero de 1920 ya estipulaba que "el armamento, la disciplina, la forma de luchar contra el enemigo, las trincheras, demuestran que las pandillas que nos atacaron no son simples pandillas de bandidos, sino tropas entrenadas" (David: 80-104).

Esta revuelta del norte de Siria, que duró hasta 1921, fue una primera expresión de la resistencia local al colonialismo derivado de la descomposición del imperio otomano. Si bien estaba compuesta fundamentalmente por aldeanos, sus líderes a menudo se encontraban entre las figuras más notables de las principales ciudades, como Alepo. Destacan, entre ellos, el líder de origen kurdo Ibrahim Hanano, o el Sheikh Jabal Hussair. También contaba con el respaldo de autoridades religiosas, como el prestigioso Sheikh Saleh Al Ali, miembro de una importante familia notable alauí. La movilización partía de motivaciones variadas en las que se entremezclaban las cuestiones más locales y rurales, como la defensa de territorio, y el argumentario islámico de resistencia contra la imposición de una visión cultural en la tierra del islam (Dar Al Islam).

Según los servicios de inteligencia franceses, las montañas de Jabal Shaykhoun, en Latakia, era una de las zonas más activas, y el líder local más relevante allí era Omar Bitar. Fue a su guerrilla a la que se unió Al Qassam, estableciendo su primera base en el pueblo de Zanqufa y participando en

unanimidad sobre su significado. Según Luz Gómez, ha habido incluso escuelas de doctrina que han considerado a la yihad como el sexto pilar del islam, si bien es cierto que en el islam sunní oficial nadie la reconoce como tal. Además, existen otras subdivisiones dentro de yihad, a veces relativas más al método que al significado en sí mismo. Es el caso de la yihad bil saif, literalmente, "yihad por la espada", que puede ser lo más cercano a esa traducción que habitualmente se hace de yihad como "guerra santa (Gómez, 2019: 416-420). 
ataques contra los franceses. La presión militar francesa hizo que tuviera que retirarse a Alepo, donde se unió a otras guerrillas o incluso pudo llegar a liderar su propia milicia en la costa norte de Siria (Sanagan, 2013:.330, Nafi, 1997:189). ${ }^{5}$ Cuando las revueltas fueron sofocadas, Al Qassam fue condenado a muerte 'in absentia' por los tribunales ocupantes. Proscrito, se vio obligado a huir a Haifa, Palestina, entre finales de 1920 y principios de 1921, y fueron sus contactos con influyentes familias notables de Damasco los que le facilitaron la huida. Pero esta experiencia guerrillera ya le había otorgado dos valiosos instrumentos: en primer lugar, un relevante prestigio que terminaría siendo una fuente de legitimidad muy eficaz; en segundo, una cualificación y experiencia miliciana, tanto en el liderazgo y la táctica como en el manejo de armas.

\section{Llegada a Palestina}

Al Qassam llegó a Haifa en un contexto propicio para la propagación de su discurso anticolonialista. Los años de lucha contra los franceses en su Siria natal fueron también años convulsos y de drásticos cambios en Palestina. Tras la descomposición del imperio otomano, la Sociedad de Naciones construyó una administración territorial que fue encomendada a Reino Unido. El Mandato británico que entró en vigor en 1922 en realidad era un reconocimiento formal de una administración que Londres ya ejercía desde 1917.

Desde el punto de vista político, ese bienio de 1920 a 1922 fue beneficioso para el sionismo. El 18 de junio de 1922, Londres publica lo que se conoce como el Libro Blanco, una declaración política que, si bien asume que los judíos están en Palestina por derecho propio y que representan una comunidad con aspiraciones nacionales que darán lugar a su futuro hogar, eso no significa que toda Palestina vaya convertirse en el "Hogar Nacional Judío". La carta del Mandato británico, que guiaría las políticas de Londres en su administración del territorio y que fue ratificada por la Sociedad de Naciones, respaldaría esta idea, reconociendo a la Agencia Judía, principal agencia sionista internacional, como organismo hebreo interlocutor y resaltando su compromiso de favorecer en todos los terrenos la creación de un hogar judío (Culla, 2005: 97-136).

Como señala Swedemburg, Haifa era uno de los centros más importantes de las estrategias económicas británicas en la región, pero también del desarrollo económico judío. Su puerto era el término del importante oleoducto que llegaba desde Irak y que suministraba combustible a la Marina británica en el este del Mediterráneo. Pero, además, era el puerto receptor más importante y una de las localidades del Mandato que más sufrían la inmigración dirigida por las organizaciones sionistas, especialmente la Agencia Judía. Una migración que estaba modificando significativamente la estructura de la sociedad y generando no pocos conflictos internos. Además, hasta la partición colonial tras la I Guerra Mundial, Siria y Palestina era una única unidad territorial dependiente del Imperio Otomano y las fronteras no se establecieron hasta que en 1920-1922 se configuraron los mandatos a Francia y Reino Unido. Numerosas ramas de las familias se encontraban dispersas en ambos territorios y la relación social y económica era fluida entre localidades como Damasco y Haifa, por ejemplo (Álvarez-Ossorio, 2020: 105).

\footnotetext{
${ }^{5}$ Esta etapa de Al Qassam es una de las más inciertas. Como señala Sanagan (2013) no está claro si lideró el grupo o se unió a él. Otros autores como Moubayed (2005) dan por hecho que comandase su propia milicia. En cualquier caso, lo que sí parece fuera de duda es que es su primera experiencia guerrillera. Sin embargo, esta etapa plantea también la duda de si su lucha estaba estrictamente dirigida contra la ocupación francesa o abarcaba además el enfrentamiento contra la secta alawí, dominante en la región de Latakia, lo que aportaría una dimensión sectaria a su visión sobre el islam y la lucha por él.
} 
Los primeros años del clérigo sirio en el territorio del Mandato británico en Palestina son los de la llamada Tercera Aliá (ascenso, en hebreo) u oleada migratoria. Atraídos por las consideraciones de la Declaración Balfour de 1917, el reconocimiento del Libro Blanco y la carta del Mandato, entre 1921 y 1931 la población judía en Palestina se duplicó (Sanagan, enero de 2013: 333). Sólo entre 1919 y 1923, se establecieron unos 37.000 judíos (Culla, 2005: 97-136). El porcentaje de la población judeopalestina en 1923 ya era del 13\% del total y creciendo. En su mayoría, eran jóvenes judíos de la diáspora europea, instruidos en el trabajo agrícola que pasarían a engrosar la fuerza campesina y obrera, entrando en colisión clara con la población local árabe. El liderazgo palestino, encabezado por las estructuras del islam institucional y su líder el Gran Muftí de Jerusalén, Hajj Amin Al Husseini, estaba inquieto por este crecimiento de la inmigración y frustrado por su incapacidad para detenerla. La profunda división en el liderazgo político y religioso palestino convertían en poco efectivas las acciones emprendidas para contrarrestarlo.

Al Qassam se instala en Haifa en este contexto. Desde el puesto de maestro en la escuela Al Burj que consiguió respaldado por la legitimidad que le otorgaba su trayectoria en Siria, pronto comenzó a predicar como imam en la mezquita Istiqlal el mensaje anticolonial que ya sostenía en su país y encontró su mayor audiencia en las zonas más empobrecidas del puerto. La escuela se convirtió en uno de los grandes centros del pensamiento de la 'salafiya' en Palestina. Estaba dirigida por Kamal Al Qasab (1873-1954), un notable líder también de origen sirio y miembro de una influyente familia en el país vecino con la que tenía una gran sintonía ideológica. Durante esos primeros años, ambos fueron aliados doctrinales, llegando a firmar un polémico panfleto conjunto en el que criticaban como poco rigoristas las prácticas en las liturgias de los funerales (Scheleifer, 1993:143; Nafi 1997:190).

Aunque sus primeros cargos no fueron los únicos ni los más importantes, sí fue la manera en la que comenzó a ganar prestigio entre la comunidad musulmana local. Progresivamente se convirtió en predicador en la mezquita de Jerena y miembro de importantes organismos del islam institucional, como la Corte de la Sharía. Su discurso, al principio más social que político, caló entre la sociedad más humilde y se basaba en tres puntos: regreso al fundamento de la fe, emprendimiento de una reforma del islam institucional y un combate -metafórico- contra lo que denominaba "prácticas folclóricas" (Milton-Edwards, 1996: 16). Ya desde 1924, gracias a su carisma, comenzó a crear un pequeño grupo de seguidores elegidos personalmente por él que seleccionaba entre los más concentrados en la oración y los más receptivos a sus sermones.

Poco a poco, su dialéctica comenzó a incluir mensajes cada vez más extremos, apelando a la yihad armada contra el Mandato británico (Sanagan, enero de 2013:336). Su mensaje también incluía fuertes críticas a la estrategia del islam institucional, que se limitaba a dictar fatwas o edictos islámicos contra la emigración sionista y la política británica, por considerarla inútil. Su mensaje también incorporaba una característica novedosa y a la que no se había referido hasta entonces ninguna estructura religiosa: para Al Qassam, la yihad implicaba, necesariamente, una rebelión social en favor de los pobres. De hecho, sus seguidores más fieles provenían de los estratos sociales más bajos, desde los empobrecidos barrios de los alrededores de los muelles de Haifa, hasta los campesinos provenientes de toda Galilea que habían perdido sus tierras tras ser adquiridas por el Fondo Nacional Judío, la gran estructura económica de sionismo que se encargaban de comprar tierras para los migrantes judíos.

La reputación de Al Qassam como combatiente contra la ocupación en Siria le otorgó, además, un gran crédito entre los jóvenes, frustrados por la inmigración y el desempleo. También su activismo social, ya que que involucró no sólo en las cuestiones litúrgicas, sino que fundó una escuela nocturna para pobres y recaudó fondos para los desempleados. (Nafi, 1997:194) Esto reforzó su popularidad y autoridad. En 1928 cofundó y lideró la rama de Haifa de la Asociación de Jóvenes Musulmanes, lo que le otorgó status y acceso a familias y clanes notables y, gracias a esta posición, Al Qassam 
estableció contacto con el partido nacionalista Istiqlal, una relación que le otorgó cierta protección política a medida que en su discurso incrementaba los llamamientos a la lucha armada religiosa.

La popularidad de Al Qassam y su traducción en la influencia política ha sido analizada a menudo por su relación con altas autoridades palestinas. Quizá, uno de los casos más significativos, sea la relación del clérigo con el Gran Muftí, Hajj Amin Al Husseini, líder de la familia Husseini, que ostentaban la relevante consideración de jerife o descendiente del profeta Mahoma. Hajj Amin fue una figura clave de la historia palestina contemporánea. Biógrafos del Muftí, como el historiador y rabino David G. Dalin ni siquiera le mencionan a Al Qassam, pero llan Pappe, autor de una de las mejores investigaciones sobre la familia Husseini, insiste en señalar que pudo ejercer una considerable influencia en Hajj Amin. Incluso, señala que el apoyo del clérigo sirio fue un factor importante en la elección de Hajj Amín para el poderoso cargo de Gran Muftí (Pappe, 2017: 214). Pero lo que no genera lugar a dudas es que el clérigo sirio logró la suficiente confianza como para que Hajj Amin, una vez al frente de su cargo, financiase inicialmente sus proyectos sociales. Sin embargo, como bien resalta Schleifer (1993), "Al Qassam nunca se unió a ninguna formación política, ni al Istiqlal ni a los seguidores de Al Husseini", como tampoco hubo muchos seguidores nacionalistas que se unieran a él.

También se ha tratado de vincular, a menudo, a Al Qassam con los Hermanos Musulmanes palestinos, aunque este vínculo corresponde más a una cierta tradición oral que a fuentes solventes. Esa filiación no fue, en realidad, posible y eso se puede concluir con un análisis cronológico de la instauración de la Hermandad en Palestina. Creados en Egipto en 1928, la vocación transnacional de la organización de los HHMM le empujó a expandirse en todos los países árabes y musulmanes, y Palestina fue, por cercanía y condiciones, el primer objetivo. Pero no fue hasta 1945 cuando Hassan Al Banna, líder y fundador de la Hermandad, encargó a su más estrecho colaborador y yerno, Said Ramadán, la tarea de formar las primeras ramas de la organización en la región.

Esa función de Ramadán, según el historiador palestino El Awasi, se produce en tres etapas y distintos viajes, no sólo por Palestina: Una primera etapa para iniciar los contactos para conseguir apoyo para la creación, una segunda para monitorizar el proceso y supervisarlo, y una tercera y última para impulsarlo, que se verá truncada por su expulsión y la prohibición por parte de las autoridades británicas de volver a la zona (El Awasi, 1998: 152).

Durante su primer viaje, Ramadan comienza los contactos para conseguir la 'masa crítica' de apoyo que permitiese lograr el establecimiento de las primeras ramas. Lo hace manteniendo reuniones con los líderes de las familias notables y jeques de las principales ciudades y núcleos de población: Nablús, Ramallah, Bersheeba, Ramlah y Jericó. Sin embargo, ese primer momento resultó ser ejemplo clarificador de las características de las fuentes de legitimidad social y de las "fuerzas profundas" más importantes de Palestina: el clan y la familia notable. Ramadán encontró como principal obstáculo que los jeques de esas familias se consideraban los adecuados para establecer la religión y la sociopolítica de sus localidades y reclamaban la máxima autoridad en las respectivas ramas.

El enviado de Al Banna comprendió la complejidad de las fuentes locales de autoridad moral y así se lo transmitió en una carta dirigida a Hassan Al Banna en la que hace un balance de la situación y sacando dos conclusiones: La primera, que para lograr una exitosa construcción de los HH.MM. en la zona habría que alcanzar un acuerdo con la autoridad más importante dentro del complejo entramado de clanes de Palestina: ese no era otro que el Gran Muftí de Jerusalén, Hajj Amin Al 
Husseini, que ya era la figura más relevante de una de las dos familias más relevantes de Cisjordania, los Husseini, que se disputaban el poder y la influencia con la también familia notable Nashashibi.

La segunda conclusión, que una exitosa formación de la Hermandad implicaba abordarla teniendo en cuenta, también, el factor generacional. Según El Awasi, "Ramadan sostenía que la causa de Palestina era una causa para los jóvenes: "¿Cómo se puede formar una sociedad juvenil, se preguntó, sin provocar que los Sheikhs (jeques) ancianos estuvieran en contra?. Ramadán terminó eligiendo hombres ancianos que les gustaba tanto jóvenes como viejos"(El Awasi 1998: 152).

Ambos factores, el clánico y el generacional, resultaron determinantes en la creación y personalidad de las ramas palestinas de los HHMM. La primera de ellas se fundó en Jerusalén entre 1945 y 1946, (Hroub, 2002: 15). A ella siguieron otras cuatro (Haifa, Hebrón, Jaffa, y Gaza). Para todas ellas, la dirigencia de los HH.MM. en El Cairo llegó a acuerdos con los jeques más importantes de cada localidad. A la inauguración de la sede de Jerusalén, por ejemplo, acudieron figuras como el propio Hajj Amín, así como representantes de los Nashashibi. En 1947 ya existían 25 ramas con entre 12.000 y 20.000 miembros (Milton-Edwars, 1996: 33).

Sin embargo, en ninguno de estos procesos hubo contacto con Al Qassam. Para cuando Ramadán llegó a Palestina, el clérigo sirio ya había muerto y era un mito. Ni siquiera los reductos que aún quedaban de sus seguidores tuvieron contacto directo con él, si bien es cierto que el clérigo sirio había abonado el terreno en el norte del país para que fuera receptivo a la configuración de una alternativa política de inspiración islámica.

\section{El comienzo de la yihad armada}

La primera década de Al Qassam en Palestina fueron los años en los que se comenzó a construir la cultura de resistencia armada. Según Sanagan (2016), entre 1929 y 1933 existieron tres organizaciones milicianas relevantes en Palestina. La primera, Al Kaff Al Khadra (Mano Verde), que operaba en la zona de Acre, Safed y Nazaret. La segunda, Al Jihad Al Muqqadas, liderada por Abdelqader Al Husseini, sobrino del Gran Muftí, operaba en las inmediaciones de Jerusalén. La tercera fue Al Kaff Al Aswad (Mano Negra), organizada y creada por el propio Al Qassam en torno a Haifa y Galilea. Sin embargo, su impacto era limitado. Militarmente, ninguna gozaba de una logística sofisticada ni "intentaban crear una infraestructura de potencial gobierno alternativo" (Bowden, 1975:151-152).

El paso a la acción guerrillera del clérigo sirio, que comenzó en 1930, tiene un punto de partida: la fatwa dictada por Badr Al Dine, máxima autoridad religiosa de Damasco, que declaró una lucha armada contra el Mandato británico y que Al Qassam respaldó. Como resalta Schleifer (1993), el clérigo leyó la convulsión social, política y económica en términos religiosos. Su respuesta fue totalizante. Había partido de una yihad moral, social y política y terminaba conduciendo, casi de manera inevitable, a la yihad armada. El momento clave, según autores como Mohsen (año), fue la ejecución de tres milicianos palestinos por parte de las autoridades británicas el 17 de junio de 1930. El periodista del diario palestino Filistín Abd El Ghani Al Karmi se cruzó con Al Qassam dos días después y le retrató así: "Le vi con una cara sombría, superando una lágrima, en sus ojos había una terrible chispa y su cuerpo temblaba de rabia. Era casi inconsciente de su entorno. Le vi dirigirse rápidamente a la mezquita y le seguí. Allí lanzó un sermón fiero” (Schleifer, 1993:147).

Esas ejecuciones y la fatwa de Damasco, impulsaron a Al Qassam a construir su organización armada. Su base la estableció al norte de Nablus. El primer paso fue organizar pequeños grupos secretos para adiestrarlos en el manejo de armas, unas primeras células que confluyeron en la organización 'La Mano Negra'. Para Al Qassam, el proceso se dividía en dos: la yihad individual y la yihad social. Desde su perspectiva, el muyahid o guerrero no era el resultado de una voluntad interna, sino que era elegido por Dios. Eso implicaba por su parte una sincera perfección en el ejercicio de rituales y liturgias, en la creencia y fe, así como una auténtica sumisión de los individuos 
a los Comandos de Dios. Para el clérigo sirio, el carácter era más importante que la fuerza, e insistía y predicaba en el combate a la degradación de los principios islámicos (Ibidem, 145).

Los primeros círculos de Al Qassam eran conocidos como Al Mashayikh (en árabe, los jeques) nombre con el que captaron la atención de los servicios de inteligencia británicos y sionistas. La apariencia física era identificativa, y su mayor característica eran unas largas barbas, imagen en la que el propio Al Qassam insistía. El clérigo remarcaba importancia de la espiritualidad del grupo, recomendando a sus seguidores participar en ejercicios espirituales y otras prácticas rituales probablemente recibidas del sufismo aprendido por su contacto con cofradías como la Qadiriya.

Según Schleifer (1993), Al Qassam era muy estricto en los entrenamientos de los candidatos a formar parte de su organización armada, candidaturas que estaban limitadas a un número muy reducido y selecto de sus seguidores. Les hacía dormir al aire libre en las montañas a bajas temperaturas, marchar sin comida ni agua o dormir una o dos veces en el suelo. Tras las jornadas de entrenamiento, mandaba a sus seguidores a sus pueblos natales y les instaba a involucrarse con la gente de la calle y preparar así el terreno para sus viajes personales en los que él mismo reclutaría a nuevos seguidores. Sus seguidores y potenciales milicianos surgían de estratos sociales variados, aunque siempre de clase humilde, como trabajadores, campesinos y nómadas. Respecto a la seguridad de la organización había una regla inviolable: mantener un máximo secretismo sobre los entrenamientos (Schleifer 1993: 147).

La "Mano Negra" nació en Haifa, donde la figura de Al Qassam tenía una gran popularidad entre la población humilde. Se diseminaba en círculos secretos, la mayoría de ellos en el campo, y según algunos autores, llegó a tener presencia incluso en zonas lejanas como Gaza. Ciertamente, existe una gran confusión sobre el número real de integrantes. Schleifer ni siquiera ofrece un número aproximado, mientras que Milton Edwards y Mohsen lo estiman en unos 200 miembros regulares y unos 800 seguidores.

Cada miembro sólo conocía a los integrantes de su círculo y las células estaban lideradas por un naquib (comandante). La cadena de mando estaba estructurada de forma piramidal, liderada por un consejo formado por Al Qassam y otras cuatro personas en sus inicios, aunque posteriormente serían 12 personas. Se trata de un esquema que se ha repetido en todas las estructuras islamistas, desde los HHMM hasta organizaciones como Yihad Islámica Palestina o Hamas. Se dividía en cinco unidades, cada una centrada en distintas tareas: compra de armas, entrenamiento militar, espionaje, propaganda y comunicaciones políticas (Mohsen, 2014:.140).

Al Qassam había buscado apoyos más tácticos que ideológicos antes de iniciar la lucha armada, tanto locales como internacionales, aunque sin éxito. Según algunos autores, estableció contacto con la Roma fascista, con la esperanza de que el Gobierno de Mussolini pudiera financiar su causa, pero las autoridades italianas se negaron a hacerlo Fuente?. Después, lo intentó con el gobierno nazi, utilizando para ello su conexión con Hajj Amin, quien ya había comenzado a establecer contacto con los alemanes, pero el régimen de Hitler le remitió a otros movimientos árabes (Moubayed, 2005: 391).

En la arena local, Al Qassam había tratado de persuadir al Gran Muftí de Jerusalén para emprender una yihad armada contra los británicos y los sionistas, pero éste aún apostaba por una táctica más política que militar. En su intento por convencerle, Al Qassam utilizó varias estrategias, entre ellas, enviar a uno de sus hombres de confianza, Mahmud Salim, a proponerle una acción conjunta: mientras él iniciaba una revuelta armada en el norte, proponía que el Gran Muftí iniciara otra 
simultánea en el sur. Pero la estrategia de Hajj Amin pasaba por una presión regional árabe sobre los británicos, y no veía aún claro el momento de iniciar una lucha armada. Sólo otro influyente líder palestino tuvo conocimiento de sus intenciones, Haifan Rashid Al Hajj Ibrahim, el líder del Istiqlal, quien tampoco se involucró (Pappe, 2017: 214; Basheer, 1997:211).

Así pues, Al Qassam y sus seguidores se lanzaron solos a la lucha armada entre finales de octubre y principios de noviembre de 1935. Se escondieron en las montañas para iniciar sus ataques guerrilleros contra las tropas británicas, aunque las fuentes sobre el inicio de esta campaña no están claras. El momento de referencia, en cualquiera de ellas, fue la declaración pública de noviembre de 1935 por parte de líderes árabes contra la Declaración Balfour en el XVIII aniversario de la misma. Según algunas fuentes, Al Qassam que fue uno de los que la realizó, comenzó su lucha un mes antes, pero otras fuentes posteriores lo sitúan entre el 1 y 6 de noviembre (Sanagan, enero de 2013: 345).

Los ataques no se dirigían contra civiles y distinguían, asegura Pape, entre policías judíos y musulmanes. Pero la lucha guerrillera de Al Qassam y su círculo estrecho de seguidores duró pocos días. El 22 de noviembre de 1935, en los alrededores del pueblo de Sheik Zeid, Al Qassam y cuatro de sus milicianos murieron en un enfrentamiento con el ejército británico. Otros cinco líderes de la organización "Mano Negra" fueron capturados.

En el momento de su muerte, Al Qassam ya había generado una buena corte de seguidores y su funeral se convirtió en una escenificación de su influencia. Celebrado en Jerena, a él acudieron cerca de 3.000 personas de muy diverso perfil social, desde trabajadores y campesinos hasta miembros de la alta burguesía y la élite política árabe. ${ }^{6}$ Entre los asistentes, cuya afluencia sobrepasó las estimaciones de las autoridades británicas, había personalidades como el director del Banco Árabe, Rashid Al Hadj Ibrahim, o el antiguo cadí (gobernante o juez en territorios musulmanes) de la Meca, el jeque Yunís Al Jatib. La influencia de Al Qassam hizo que las autoridades británicas en el Mandato llamaran la atención de Londres:

"89. A principios de noviembre se supo que un grupo "terrorista" se había establecido en las colinas de Galilea, bajo el liderazgo del jeque Izzed Din al Qassam, un refugiado político de Siria con una amplia reputación como líder religioso. La banda fue capturada por la policía cerca de Jenin, y cuatro de sus miembros asesinados, incluido el Sheikh Izzed Din. Una gran multitud de árabes asistieron a su funeral en Haifa, y hubo alguna manifestación en la que se arrojaron piedras. Los periódicos árabes lo aclamaron como un mártir de su nación y su fe. "Querido amigo y mártir", dijo uno de ellos, "te escuché predicar desde una plataforma descansando en una espada. Hoy eres, por la voluntad de Dios, un predicador mayor de lo que nunca fuiste"(Cabinet Memorandum, Catalogo $\mathrm{CAB} / 24 / 270$ : 89).

Tras su muerte, la organización no desapareció completamente. El relevo lo tomaron estrechos colaboradores, primero liderados por Hussein Hamadi y, posteriormente, por el jeque Farhim Saadi. Los 'qassamitas', continuaron con esporádicos ataques así como participando en numerosas huelgas y movilizaciones. Según documentos la Public Record Office, inundaron las poblaciones árabes de propaganda incitando a la revuelta, siguiendo el ejemplo de su líder. Los informes de la inteligencia detallan que hasta 50 líderes religiosos estuvieron envueltos en las acciones posteriores a la muerte de Al Qassam (Milton-Edwars, 1996: 20). Sin embargo, aunque presente en las calles, en 1936 el movimiento surgido tras el inicio de su guerrilla estaba prácticamente ausente de la arena política. Sus líderes se encontraban en las montañas continuando con la guerrilla que había iniciado el clérigo sirio y el movimiento desapareció con la captura y ejecución de su sucesor, Farham Saadi, el 27 de noviembre de 1937.

\footnotetext{
${ }^{6}$ La prensa lo presentaba local ya lo presentaba como un "mártir de la nación y la fe" (Bowden, T,1975:150)

${ }^{7}$ Traducción al inglés de Sanagan, también usado por Mohsen, del término "Al Qassamiyun" (Sanagan, 2020: ix)
} 


\section{Los mitos sobre Izz al Din Al Qassam y su influencia}

Hoy, la tumba de Al Qassam dista hoy mucho de ser un mausoleo. Situada en el poblado palestino de Balad al Sheykh, a siete kilómetros de Haifa, consiste tan sólo en una pequeña lápida antigua que en ocasiones ha sido objeto de profanaciones por parte de radicales sionistas. Pero las referencias al clérigo trascienden esta discreta sepultura. En Gaza, una de las calles que conducen al hospital Al Shifa, el más importante de la capital de la Franja, lleva su nombre. También en Ramala, capital administrativa de Cisjordania, la vía que conduce a la sede de la Presidencia palestina se llama Izz Al Dine al Qassam.

La leyenda del clérigo sirio ha traspasado las fronteras. Hay calles con su nombre en Alepo, Jayrud, en la provincia de Damasco, o Jordania; mezquitas, como la del campo de Nuseirat de Gaza, o en la ciudad de Nablús que le rinden homenaje. Aparece en libros de texto en las escuelas palestinas, y hay comics, novelas e incluso una serie de ficción de la televisión estatal siria sobre su historia. (Sanagan, 2020: 145). En política, sigue siendo un potente símbolo utilizado movilizar a la población. Y es que desde su muerte, la historia de Al Qassam ha estado lejos de permanecer "fijada dentro de una narrativa hegemónica" (Swedenburg, 1987: 20).

Los trabajos científicos se han encontrado a menudo numerosos obstáculos ante la escasez de documentos y archivos y las dificultades de acceso, y muchos de los textos científicos que han tratado de reconstruir la historia han recurrido a entrevistas a supervivientes o testigos que le vieron o conocieron, así como a la interpretación de las distintas historias transmitidas por tradición oral. Todo ello ha contribuido a crear un mito o, incluso, varios: Algunos han retratado Al Qassam como muyahid (literalmente, el que hace la yihad, tradicionalmente asociado a guerrilleros. Gómez, 2019: 277-8). Otros, como nacionalista, o como reformista o como defensor de las clases humildes. Todas ellas visiones que inciden en aspectos puntuales, más o menos precisos, de su historia con el fin de reforzar valores políticos posteriores.

De todas las visiones locales, una de las más extendidas es sin duda el nexo de unión entre Al Qassam y la revuelta de 1936, la primera gran revuelta palestina. Este levantamiento se produjo un año después de su muerte y hace que "la identificación de Al Qassam con la revuelta es muy poderosa" (Swedenburg, 1987:20). No sólo en la tradición oral, o la cultura política palestina, sino también entre la literatura académica árabe. El Awasi, por ejemplo, considera que "el pueblo palestino no ha olvidado que la revuelta de 1936 fue instigada por Shaykh Al Qassam y no por un erudito musulmán palestino" (El Awasi, 1998:159). También Mohsen, Hammuda o Nafi, historiadores palestinos, consideran que la guerrilla iniciada por el clérigo en Haifa fue el detonante del levantamiento. Además de su rol como iniciador de las revueltas de 1936, otras discusiones sobre Al Qassam también han encontrado eco en la literatura académica. Mark Sanagan establece tres categorías dentro de la literatura biográfica sobre el líder sirio (Sanagan, enero de 2013: 325): la literatura inglesa, la árabe y la literatura de internet, y cada una de ellas hace hincapié en distintas facetas de su vida.

Dentro de esa bibliografía, destacan fundamentalmente a tres biógrafos. En primer lugar, Abdullah Schleifer(1993), que aporta como principales contribuciones la importancia doctrinal de la corriente islámica sufí en Al Qassam, y su visión sobre la justicia social y la ética islamista, presentándolo como un activista preocupado por la moral de la comunidad y la sociedad. En segundo, Basheer Nafi (1997), que señala que fueron las ideas 'salafiya' y no las sufíes las que caracterizaron a Al Qassam y que presta una mayor atención a su desarrollo político y las relaciones con otros líderes. Por último, Shai Lachman que señala que todo lo que Al Qassam hizo estuvo al servicio de sus principios 
religiosos (Sanagan, enero de 2013: 320) También existen estudiosos dentro de la literatura académica árabe, como en el caso de Abd al Sattar Qassim (1992), que presentan al clérigo como un nacionalista autóctono y anticolonialista, matizando que su cierta semántica islamista no fue más que una particularidad del anticolonialismo en Oriente Próximo. Todas estas visiones presentan la difícil tarea de catalogarle tanto a él como a su movimiento, ya sea desde una óptica nacionalista como desde la del islamismo armado en Palestina.

Prácticamente desde su muerte, el mito ha permanecido en culturas políticas y contextos diferentes. A él han recurrudo desde líderes y organizaciones palestinas contemporáneas, como el partido Al Istiqlal, como otros posteriores. Por ejemplo, en los años cuarenta, Al Qassam fue una de las primeras influencias de Taqui Ad Din An Nabahani (1914-1977), fundador y guía de la organización islamista Hizb At Tahrir creado en 1953 (Milton-Edwards, 1996: 65). Pero es en los años 80, cuando su figura recobra presencia de la mano de los movimientos islamistas, que han tratado de adueñarse de su figura en busca de continuidad y legitimidad histórica. Para el grupo Yihad Islámica Palestina, el primer grupo islamista armado en palestina nacido en 1985, Al Qassam es una fuente de inspiración que unía el islamismo, la lucha armada y la cuestión nacional palestina. Su nombre está vinculado a no pocos símbolos del grupo. Por ejemplo, el principal bastión desde donde YIP construyó su organización y donde se centralizaban todas sus acciones, precisamente, la Mezquita Al Qassam de Gaza. Desde allí sus líderes predicaban sus mensajes, resaltando precisamente su dimensión guerrillera (Hatina, 2001: 47).

En Hamas, las referencias han sido incluso más constantes desde los primeros meses de la organización en 1988. Entre sus menciones más relevantes se encuentra la del artículo 7 de su Carta Fundacional (Mithaq fi Harakat Al Muqawama Al islamiya) donde le considera, junto a los HHMM, como el principal antecedente de su lucha y considera a la propia organización como "un eslabón de la cadena de la yihad" iniciada por él. También le dedicó, desde sus primeros meses, boletines y panfletos de alabanza a su ejemplo (Mishal, 1994: 245). En 1992 bautizó su recién constituido brazo armado con su nombre, las Brigadas del mártir Izz Al Din Al Qassam, en un exitoso intento por adueñarse de su legado, así como de definir un relato del contenido de su pensamiento y acciones.

[Fig. 2.- Carteles de distintas organizaciones y sobre Izz Al Din Al Qassam] ${ }^{8}$

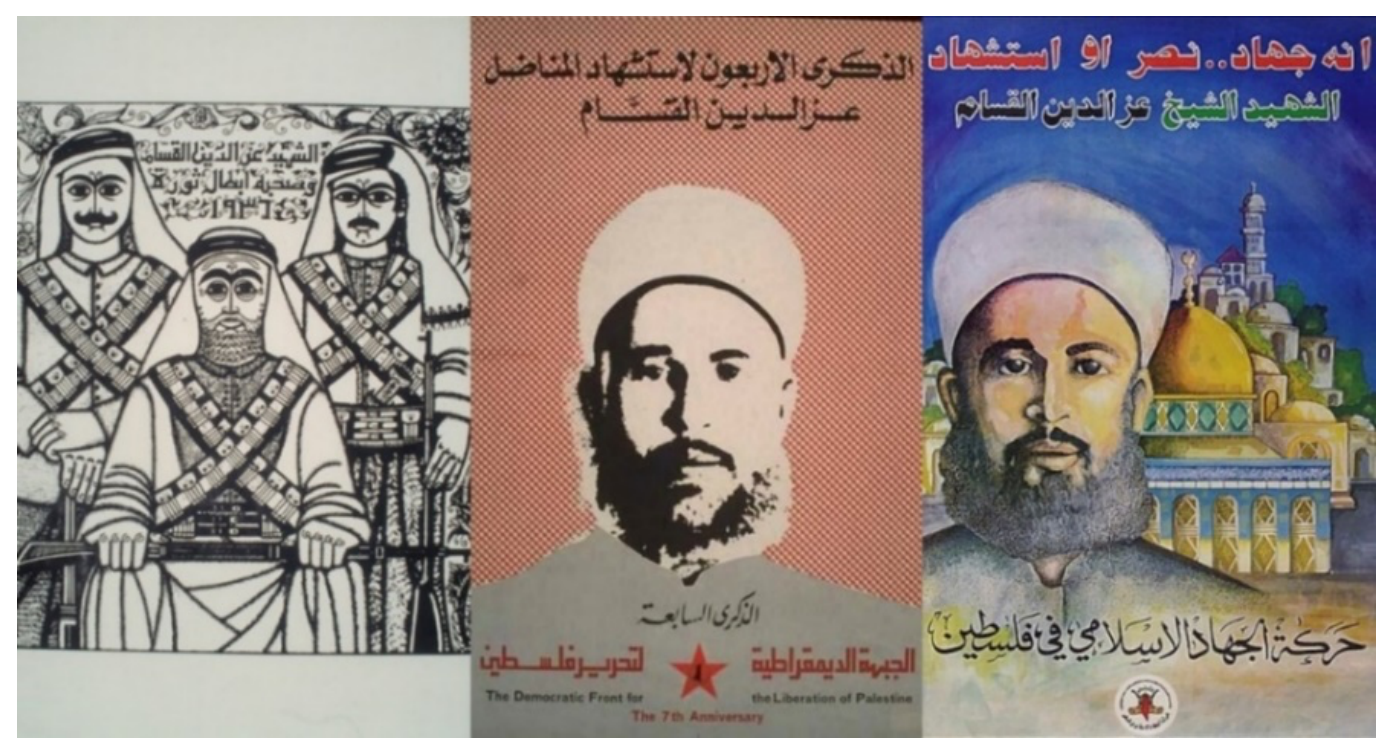

\footnotetext{
${ }^{8}$ Fuente: Palestinian Poster Proyect Archives. https://www.palestineposterproject.org/ [consulta: 22 de octubre de 2020]
} 
Sin embargo, el relato islamista no es el único. Existen grandes debates en torno a la verdadera naturaleza del pensamiento de Al Qassam y sus seguidores dentro del movimiento palestino. A menudo, el clérigo sirio aparece retratado como un luchador de la nación palestina, un pionero que se mezcla con otros guerrilleros. Desde su muerte en 1935, partidos palestinos como Istiqlal, el Frente Popular para la Liberación de Palestina o Al Fatah han recurrido a Al Qassam como ejemplo de imitación. Cada una de estas formaciones políticas ha resaltado a un aspecto de su personalidad y pensamiento. Al Fatah, su lucha contra el sionismo, para retratarle como un héroe de la nación.

Un ejemplo claro puede observarse durante los primeros años de la Primera Intifada, en los que el Mando Nacional Unificado, una coalición de grupos armados palestinos no islamistas, dedicaron hasta seis comunicados a Al Qassam, siempre, bajo el mismo menaje, el del clérigo sirio como padre fundador de la lucha armada palestina: "Oh, pueblo de mártires, descendientes de Al Qassam. Oh, hermanos y camaradas de Abu Sharaf, Khalid Nazzal y Kanafani” (En Mishal, 1994:55).

A él ha recurrido también el marxista Frente Democrático para la Liberación de Palestina, de orientación maoísta, destacando su lucha contra el colonialismo y su visión revolucionaria por la justicia social. Incluso, otorgándole un peso en su historia. Un ejemplo relevante es el cartel de la fig.2 (cartel central) en el que se celebra el 40 aniversario de la muerte de Al Qassam y la fundación del grupo en 1976. Todas ellas visiones incompletas sobre su pensamiento, pero oportunamente escogidas para incrementar la legitimidad de su interpretación de la causa palestina. Porque, sobre todo, Al Qassam es un héroe en la cultura popular. Un año después de su muerte, su figura seguía presente en la prensa palestina:

[Fig 3. Al Qassam junto a los líderes de las familias Husseini y Nashashibi, a los que habría acercado]. ${ }^{9}$

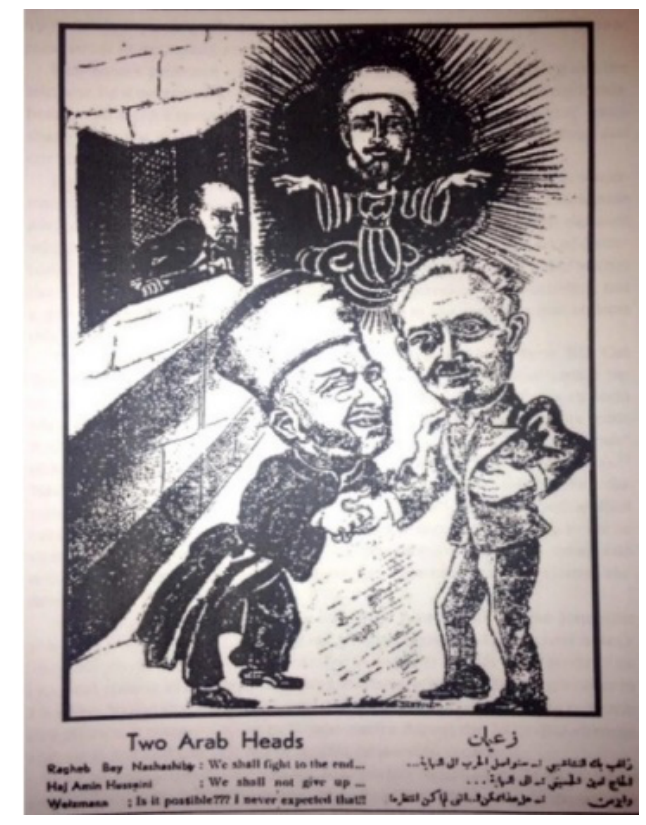

9 "Two arabs heads", Filistin, 12 de julio de 1936 (Sanagan, 2016: 25) 
También la literatura palestina le ha dedicado algunos esfuerzos. Quizá el ejemplo más representativo lo encontramos en el poema de Nuh Ibrahim, uno de los poetas palestinos más populares. En 1935, tras la muerte del clérigo, compuso la siguiente obra (Shabeeb, julio de 2004):

"Izz Eddin what a loss, a martyr for your people Who can deny your noble self, a martyr for all Palestine.

Izz Eddin rest in peace, and may your death be a lesson to all Ah ... we wish you'd remained, oh leader of the fighters.

You forsake self and wealth for the liberty of your land! When you faced an enemy, you fought with valor and pride.

You formed a troop for the fight until the land is liberated. Its goal is victory or martyrdom, and enthusiastic men you have gathered.

You gathered excellent men and with your wealth bought us arms. And you said onward to fight for victory to the homeland and religion

You gathered the finest of men and we pinned our hopes on you, But destiny, dear kin, intervened.

Betrayal played its role, and disaster befell us Blood flowed to the knee, but you didn't give in.

You yelled "God is Great", like an enraged lion But the outcome was divine destiny and God's desire." 10

Así, en toda la zona existe un relato popular que se ha ido distorsionando y que convierte a Al Qassam en una figura clave en la narrativa mitificada de la lucha armada por la liberación de Palestina. Esto se puede observar, especialmente, en muchas de las entrevistas y testimonios locales que numerosos estudiosos han ido recuperando en los últimos años. Pero, como recuerda Swedenburg, muchas de estas visiones coinciden con la proyección que las distintas corrientes políticas han hecho de él. A menudo, recuerda el autor, es recordado como un líder que se sacrificó por la nación, o por el pueblo, o por gente humilde (Swedenburg, 1987: 17). Es decir, encaja en cada una de las proyecciones políticas locales que se quiera transmitir.

\section{Conclusiones}

La influencia de Al Qassam ha sobrevivido desde su muerte convirtiéndose en una figura inspiradora e icónica, como fue el 'Che' Guevara para la izquierda revolucionaria latinoamericana, ya sea esta causa nacionalista o islamista. Quizás esa sea la parte en la que los palestinos están de acuerdo sobre él. Pero más allá de esa visión, hay muchas interpretaciones sobre Al Qassam, algunas, incluso, contradictorias. Numerosos sectores de la política local comenzaron a adueñarse de su historia y lucha prácticamente desde el fallecimiento. Fue retratado por la prensa y por autoridades políticas y religiosas palestinas como un mártir y muchos líderes seculares que no estuvieron en su funeral ni mantuvieron estrecha cercanía ni con sus acciones ni con su pensamiento, alabaron su ejemplo. No han faltado tampoco quienes le consideran, aún hoy, el principal artífice de la revuelta armada árabe de 1936, la primera gran acción de resistencia palestina contra la ocupación británica y la migración sionista (Milton-Edwars, 1996:20). Incluso, algunos le consideran como el fundador de esa lucha armada.

¿Pero cuál de todas es la visión más acertada? Con una identidad nacional en construcción, la historia de Al Qassam y su lucha han formado parte de la compleja configuración identitaria palestina, mezclando mitología y realidad. ¿Fue, como algunos dicen, un líder nacionalista? Aunque

${ }^{10}$ Traducción del árabe al inglés por Bilal Hijjawi con ediciones de Rochelle Davis 
es cierto que en las primeras experiencias nacionalistas de la resistencia palestina resulta difícil establecer la línea de separación entre el anticolonialismo, nacionalismo y el discurso con connotaciones religiosas, parece más acertado calificar a Al Qassam como un líder anticolonialista con inspiración ideológica de la 'salafiya' - con algunos rasgos del sufismo - que como un nacionalista.

Esta tesis se explica revisando su historia desde el comienzo, y no sólo la etapa palestina. Sus primeras experiencias armadas, tanto en el norte de África como en las montañas de Siria contra los franceses, no estaban inspiradas en la lucha por la independencia de una nación, ya fuera otomana, siria o palestina. Fue una lucha cultural contra la colonización y la influencia occidental sobre sociedades islámicas partiendo del concepto islámico de Dar al islam. Tanto en Siria como en Palestina, las acciones y discursos de Al Qassam respondían a una yihad identitaria socio-cultural, inspirada en principios sufíes y en el concepto islámico de sociedad tomado del pensamiento de la 'salafiya', pero no en la construcción de una identidad nacional específicamente y diferenciadamente palestina.

Al Qassam introdujo, además, la primera lucha armada moderna y de masas justificada totalmente en una interpretación del islam, convirtiéndose en la primera manifestación del concepto moderno de yihad armada en Palestina. Posiblemente, fue también una guerrilla islamista pionera en el resto de la región debido a sus características: organización no tribal, conceptos modernos de estructura y una identidad no nacional, sino religiosa y cultural. Era socialmente transversal e involucraba activamente a todos los sectores sociales, con independencia de rango, tribu, clan o clase. Como señala Milton Edwards, también fue el primero en combinar la lucha por la justicia social, con el argumentario religioso, una característica que encuentra cercanía con la estrategia de las principales organizaciones del islam político, entre ellos, los propios HHMM. ${ }^{11}$

En su figura y acción se pueden encontrar relevantes paralelismos con los grupos islamistas armados palestinos posteriores:

1) Su reafirmación de la identidad islámica y la capacidad de transformar esa identidad en una lucha contra una ocupación que establece sociedades no islámicas. Esa visión implicaba un regreso a los fundamentos de la fe, una urgencia de reformar las estructuras del islam y una necesidad moral de evitar prácticas folclóricas; todo ello influido por la corriente 'salafiya'. Al Qassam entendía la lucha de Palestina como 'una lucha de civilizaciones', un concepto utilizado, literalmente, por Hamas y su brazo armado (Brigadas Izz Al Din Al Qassam, Principios intelectuales, Art.1) $)^{12}$

2) Su revolución tenía una dimensión popular y de masas, logrando algo que ni siquiera había intentado el islam de las élites: introducir a la comunidad más humilde, a obreros y campesinos musulmanes, en la arena política. Algo que Hamas, décadas después, retoma cuando señala que "el pueblo palestino, en todas sus clases y estratos, y en todos los lugares de su existencia, es un cuerpo único e indivisible, y participa en la resistencia a la ocupación" (Brigadas Izz Al Din Al Qassam, Principios intelectuales, Art.5).

\footnotetext{
${ }^{11}$ Aunque, según fuentes citadas por Hroub, durante la revuelta de 1936 sí hubo voluntarios de los HHMM que lograron "infiltrarse y luchar en las zonas bajo control del grupo de Al Qassam". El clérigo, para entonces, ya había muerto. (Hroub 2002, 13)

${ }^{12}$ Accesible en línea https://www.alqassam.ps/arabic/\%D9\%85\%D9\%86-\%D9\%86\%D8\%AD\%D9\%86 [consulta: 21 de octubre de 2020].
} 
3) Su método era revolucionario, priorizando la yihad armada (yihad bil saif), y desechando, por ineficaz, la estrategia política de las fatwas o edictos islámicos dictados por el islam institucional. También Hamás recurre al mismo argumento cuando considera que "la yihad es lo que finalmente resolverá el conflicto en interés de la Ummah" (Brigadas Izz Al Din Al Qassam, Principios intelectuales, Art. 10) o Yihad Islámica cuando señala que "la guerra de guerrillas es su principal método".

4) La estructura y objetivos tácticos de su organización responden a un patrón operativo que años después adoptaron otros movimientos islamistas armados (Hroub, 2002; Hatina, $2001)^{13}$. Por principios, doctrina y método, la 'Mano Negra' de Al Qassam hoy podría ser considerada una organización yihadista. Es, por tanto, el primer gran precedente de este tipo de formaciones y quizá, el pionero más directo del islamismo armado en la región.

Todas estas características se encontrarán en la esencia ideológica de movimientos islamistas posteriores. En Hamas, se recogen en la Carta Fundacional de 1988 (Arts 7, 9 y 12) y se han ido desarrollando en los términos, utilizados por ambas organizaciones, de "yihad interna" y "yihad externa", y que combina el concepto de reforma moral de la sociedad con la lucha armada contra el enemigo exterior. En Yihad Islámica Palestina, en sus estatutos de 1985 (Arts. 1-7). Sin embargo, no existen datos que certifiquen una continuidad histórica de los 'qassamitas' con estas organizaciones.

La de Al Qassam fue la primera experiencia de insurgencia armada de motivación islamista organizada en Palestina pero que, pese a su influencia, estaba vinculada a su personalidad. Su movimiento desaparece poco tiempo después de su muerte. Fue un hombre de acción, no un intelectual o un líder político-religioso, como Hassan Al Banna, o Sayyid Qutb, intelectual islamista a quien muchos consideran el gran origen de los grupos islamistas armados. No dejó escritos teóricos ni edictos religiosos.

Alguna literatura no especializada le ha retratado como un líder de los HHMM, pero no existe ningún documento que permita sostenerlo, y un análisis cronológico de la presencia de la Hermandad en Palestina demuestra que no pudo coincidir con las ramas oficiales de la organización. Su historia, personalista, ofrece un mito que han ayudado a construir tanto el concepto moderno de yihad armada en Palestina como el de resistencia contra la ocupación.

Todo esto ha dejado un legado conceptual muy útil que explotaron las organizaciones islamistas posteriores: la combinación de la lucha religiosa, la lucha contra la ocupación y una no muy definida identificación de esos dos conceptos con la singularidad nacional palestina. Esto ha contribuido a que movimientos islamistas palestinos, prácticamente desde sus orígenes, incorporen a su discurso panislamista una dimensión nacionalista palestina, característica que no se encuentra en otros movimientos islamistas de los años 70 y 80.

\section{Referencias}

\section{Documentos y archivos}

HARAKAT AL MUQAWAMA AL ISLAMIYA, HAMAS (1988): Mithaq fi Harakat Al Muqawama Al islamiya (Carta del Movimiento de Resistencia Islámica palestina), 18 de agosto 1988, Gaza. Disponible en Intelligence and Terrorism Information Center en el Center for Special Studies (C.S.S) Disponible en https://www.terrorism-info.org.il/es/ [Consulta: 21 de enero de 2017].

\footnotetext{
${ }^{13}$ Comparar con los principios, medios, enfoques y métodos declarados por el brazo armado de Hamas, las "Kataib Sahid Izz al Dine Al Qassam", accesible en https://www.alqassam.ps/arabic/\%D9\%85\%D9\%86\%D9\%86\%D8\%AD\%D9\%86 [consulta: 21 de octubre de 2020].
} 
HARAKAT AL MUQAWAMA AL ISLAMIYA, HAMAS (1988): El mártir Al Qassam; Boletín no 31; 27 de octubre de 1988, Gaza, en MISHAL, S. y AHORI, R. (1994): Speaking Stones: Communicates from the Intifada Underground, Nueva York, Syracuse University Press, pp. 245-248.

HARAKAT AL MUQAWAMA AL ISLAMIYA, HAMAS: "Brigadas del Mártir Izz Al Din Al Qassam", Página web oficial, disponible en https://www.alqassam.ps/arabic/ [consulta: 1 de noviembre de 2019 y 21 de octubre de 2020].

AL QAYADA AL WATANIYA AL MUWAHIDA LIL INTIFADA (Mando Nacional Unificado de la Intifada): Comunicado número 2 del Mando Nacional Unificado de 10 de enero de 1988 en MISHAL, S. y AHORI, R. (1994): Speaking Stones: Communicates from the Intifada Underground, Nueva York, Syracuse University Press, p. 55.

Archivos Nacionales de Reino Unido, Colección "The Gabinet Papers", Cabinet Memorandum. Policy in Palestine, Catalogo CAB/24/270, Memorandum by the Secretary of State for the Colonies. 9 November 1937 (1937), Reino Unido.

\section{Fuentes gráficas de "Palestinian Poster Proyect Archives"}

KARKOUTLU, B. (1980): "El mártir Izz Al Din Al Qassam y sus compañeros de la heroica revolución”, Reasearch in Progress, disponible en https://www.palestineposterproject.org/ [consulta: 10 de diciembre de 2019].

KARKOUTLU, B. (1980): Al Jabha As Sabiya li Tahrir Filistín (Frente Democrático para la Liberación de Palestina, FDLP: "40 aniversario del martirio de Izz Al Din Al Qassam", 1976, disponible en https://www.palestineposterproject.org/ [consulta: 10 de diciembre de 2019].

HARAKAT AL JIHAD AL-ISLAMI FI FILASTIN (Yihad Islámica Palestina): "It's yihad. Either victory or martyrdom", 2003. disponible en https://www.palestineposterproject.org/ [consulta: 10 de diciembre de 2019].

\section{Estudios y monografías}

ÁlVAREZ-OSSORIO, I (2011): “Las paradojas del islam político en Siria”. Revista CIDOB d' Afers Internacionals, [en línea], n.o 93, pp. 163-78, disponible en https://www.raco.cat/index.php/RevistaCIDOB/article/view/240764 [consulta: 21 de julio de 2020].

ÁLVAREZ - OSSORIO, I (2020): "La herencia colonial en la Siria actual: fracturas sociales e implicaciones políticas", Miscelánea de Estudios Árabes y Hebraicos, Sección Árabe-Islam, Vol. 69, pp. 101-128. DOI: https://doi.org/10.30827/meaharabe.v69i0.1051

EL AWASI, A. (1998): The Muslim Brothers and the Palestine Question 1928-1947, New York, Tauris Academic Studies; I.B. TAURIS Publishers, disponible en https://www.jstor.org/stable/4282565?seq=1 [consulta: 21 de octubre de 2020].

BOWDEN, T. (1975): "The Politics of the Arab Rebellion in Palestine 1936-39", Middle Eastern Studies, Vol.11, №2, pp.147-174. DOI: https://doi.org/10.1080/00263207508700292

CULLA, JOAN B. (2005): La tierra más disputada: el sionismo, Israel y el conflicto de Palestina, Madrid, Alianza Editorial. 
DAVID, Jean Claude (dir.); BOISSIÈRE, Thierry (dir.) Alep et ses territories: Fabrique et politique de una ville (1868-2011), Nouvelle edition [en ligne]. Beyrotuh-Damas, disponible en https://books.openedition.org/ifpo/6657 [consulta: 31 de octubre de 2019].

GÓMEZ, L. (2019): Diccionario de islam e islamismo, Madrid, Editorial Trotta S.A. DOI: https://doi.org/10.14198/ELUA2009.23.20

HATINA, M. (2001): Islam and Salvation in Palestine, Tel Aviv, The Moshe Dayan Center for Middle Eastern and African Studies. DOI: https://doi.org/10.1017/S0026318400045168

HROUB, Khaled (2002): Hamas: Political Thought and Practice, Washington D.C, Institute for Palestine Studies, Institute for Palestine Studies, 2002

KRAIG, M. K. (2015). “The Revolt of 1936: A Revision”. Journal of Palestine Studies, 44(2), 28-42. DOI: https://doi.org/10.1525/jps.2015.44.2.28

LÓPEZ ALONSO, C. (2007): Hamás: La larga marcha hacia el poder, Madrid, Los libros de la Catarata. MILTON-EDWARDS, B. (1996): Islamic Politics in Palestine, Nueva York, TAURIS Publishers.

MISHAL, S. y AHORI, R. (1994): Speaking Stones: Communicates from the Intifada Underground, Nueva York, Syracuse University Press.

MOHSEN MOHAMMAD, S. (2011): "Al-Qassam and the Qassamite Experience"; Al-Zaytouna Centre for Studies and Consultations, disponible en https://eng.alzaytouna.net/2011/01/03/al-qassamand-the-qassamite-experience/\#.XxVRKygzaUk [consulta: 20 de febrero de 2019].

MOHSEN MOHAMMAD, S. (2014): The Palestinian Issue: Historical Background and Contemporary Developments; Al Zaytouna Center For Studies and Consuolting; Beirut.

MOUYABAYED, S (2005): Steel and Silk: Men and women who shaped Syria 1900-2000, Londres, Cune Editorial.

NAFI, B.N. (1997): "Shaykh 'Izz al Din Al Qassam: A Reformist and a rebel leader", Journal of Islamic Studies, Vol.8, №2, Oxford University Press. DOI: https://doi.org/10.1525/ips.2015.44.2.28

PAPPE, I. (2017): The Rise and Fall of a Palestinian Dynasty: The Husaynis 1700-1948, Londres, Saqi Books. DOI: https://doi.org/10.1111/j.1540-6563.2012.00328 4.x

RAMADAN, T. (2000): El reformismo musulmán: desde sus orígenes hasta los Hermanos Musulmanes, Barcelona, Ediciones Bellaterra.

SANAGAN, M. (2020): Lightning through the clouds: Izz al- Din al Qassam and the Making of the modern Middle East. University of Texas Press, 2020.

SANAGAN, M. (2016): Lightning through the clouds: Islam, community and anti-colonial rebellion in the life and death of 'Izz al-Din al-Qassam, 1883-1935, Tesis doctoral inedita, Department of History and Classical Studies, McGill University, Montreal.

SANAGAN, Mark (2013): "Teacher, Preacher, Soldier, Martyr: Rethinking 'Izz al-Dīn al-Qassām”, Die Welt des Islams, № 53 (3-4), pp. 315-352. DOI: https://doi.org/10.1163/15685152-5334P0002

SCHLEIFER, A. (1993): "Izz al-Din al-Qassam: Preacher and Mujahidin", en BURKE, E. y YAGHOUBINA, D. (eds): Struggle and Survival in the Modern Middle East, Berkley, University of California Press. DOI: https://doi.org/10.1111/j.1949-3606.1993.tb01015.x

SHABEEB, S. (2004); "Poetry of Rebellion The Life, Verse and Death of Nuh Ibrahim during the 193639 Revolt"; Actas de la Novena Conferencia Internacional del Instituto de Estudios Internacionales Ibrahim Abu-Lughod, Universidad de Birzeit, julio de 2004. Traducción del árabe en Insitute for Palestine Studies; Disponible en https://oldwebsite.palestine-studies.org/jq/fulltext/77928 [consulta: 25 de octubre de 2019]. 
SOREK, T. (2013); "Calendars, Martyrs, and Palestinian Particularism under British Rule"; Journal of Palestine Studies, 43 (1); pp. 6-23. DOI: https://doi.org/10.1525/ips.2013.43.1.6

SWEDENBURG, T. (1987); “Al-Qassam Remembered", Alif: Journal of Comparative Poetics, №7, The Third World: Literature and Consciosness, pp.7-24. DOI: https://doi.org/10.1525/jps.2013.43.1.6 